Jurnal Ilmiah Mahasiswa Kendali dan Listrik
Vol. xx, No. xx, Mounth 2020, page-page. $\mathbf{x x} \sim \mathbf{x x}$
E-ISSN: $2723-598 \mathrm{X}$

\title{
DESAIN PENGEPAKAN BARANG DENGAN COUNTER OTOMATIS MENGGUNAKAN PLC OMRON
}

\author{
Ristia Cahya Ningrum ${ }^{1}$, M.Iqbal ${ }^{2}$, S. Samsugi ${ }^{3}$ \\ Program Studi Teknik Elektro, Fakultas Teknik dan Ilmu Komputer, Universitas Teknokrat Indonesia ${ }^{\mathbf{1 2 , 3}}$ \\ ristia@gmail.com,m.qibal@gmail.com, s.samsugi@teknokrat.ac.id
}

\begin{abstract}
Received: (date month year)
Accepted: (date month year)

Based on the results of the system development, the results obtained are in accordance with the needs, namely packing and counting goods automatically. The results of the system testing show that the system has not worked before the work area is activated. Box Conveyors will run with the Goods Box. When the Box sensor is 1 then the Box Conveyor will stop and the goods conveyor will run. When the item passes the item sensor, the counter will count (maximum 3 items). After counting 3 items (items), the goods conveyor will stop. The Box Conveyor continues until the Box sensor gets input again (worth 1) when the next Box hits the Box sensor. When the next Box hits the Box sensor, the Conveyor will stop. The process will repeat.
\end{abstract}

Published : (date month year )

Keywords: Conveyor, Counter, Box, Goods

\begin{abstract}
Abstrak
Berdasarkan hasil pengembangan sistem didapatkan hasil yang sesuai dengan kebutuhan yaitu pengepakan dan penghitungan barang secara otomatis. Hasil dari pengujian sistem didapatkan Sistem belum bekerja sebelum work area di aktifkan Konveyor Box akan berjalan membawa Kotak Barang Ketika sensor Box bernilai 1 maka Konveyor Box akan berhenti dan Konveyor barang berjalan. Pada saat barang (item) melewati sensor barang, maka counter akan menghitung (maksimal 3 barang). Setelah menghitung 3 barang (item), maka Konveyor barang akan berhenti. Konveyor Box tetap berjalan sampai sensor Box mendapat masukan lagi (bernilai 1) saat Box berikutnya mengenai sensor Box. Pada saat Box berikutnya mengenai sensor Box, Konveyor akan berhenti. Proses akan berulang.
\end{abstract}

Kata Kunci: Konveyor, Counter, Box, Barang

To cite this article:

Authors. (Year). Title of the article. Jurnal Ilmiah Mahasiswa Kendali dan Listrik, Vol(1), Page-Page.

\section{PENDAHULUAN}

Dunia Industri selalu berkembang dengan penggunaan teknologi canggih dalam bentuk pengemasan barang dan sortir secara otomatis. Salah satunya yakni dengan memanfaatkan otomatisasi industri dengan menggunakan robot untuk pengemasan. engemasan meminimalisasi terkontaminasinya produk, membantu melindungi produk dari kerusakan, serta memungkinkan pemasaran dan branding suatu produk. Solusi pengemasan yang dipilih harus terukur secara investasi, mampu mempercepat waktu pemasaran, dan dapat beradaptasi dengan cepat terhadap perubahan produk melalui teknologi visi terintegrasi. Untuk proses pengemasan yang berulang dan perlu pengemasan manual secara intensif, maka solusi yang dinilai ideal yakni dengan memanfaatkan teknologi robot [1]. Selama ini sistem kendali di dalam dunia industri sering menggunakan sistem kendali Programmable Logic Control atau disingkat PLC [2]. PLC adalah sebuah alat yang digunakan untuk menggantikan rangkaian sederetan relay yang dijumpai pada sistem kontrol proses Konvensional. PLC bekerja dengan cara mengamati masukan (melalui sensor-sensor terkait) [3].

Prinsip kerja dari PLC hamper sama denga Mikrokontroller seperti ArduinoArduino dapat di masukan program untuk dapat melakukan sesuatu sesuai keinginan pemrogramnya [4][5]. Arduino Uno R3 adalah papan pengembangan mikrokontroler yang berbasis chip ATmega328P. Arduino Uno memiliki 14 digital pin input / output (atau biasa ditulis $\mathrm{I} / \mathrm{O}$, dimana 14 pin diantaranya dapat digunakan sebagai output PWM antara lain pin 0 
sampai 13), 6 pin input analog [6]. Untuk Dunia Industri dengan beban kerja dan penggunaan long time maka di butuhkan PLC. Programmable Logic Control merupakan jantung sistem pengendali atau kontrol yang sering digunakan untuk pengontrolan mesin-mesin produksi yang ada pada dunia industri istem kerja PLC yaitu dengan menguji sinyal input, kemudian memproses sinyal input dan menghasilkan sinyal output sesuai dengan program yang telah disimpan ke dalam memori [7]. Dengan penggunaan PLC dalam proses pengemasan barang dapat bekerja dengan optimal.

\section{TELAAH PUSTAKA}

Beberapa penelitian terkait penggunaan PLC dalam membuat Otomasi Pengemasan dan penghitungan barang telah banyak di buat diantaranya yaitu Rancang Bangun Konveyoe Penghitungan Barang Dengan Sistem kendali Berbasis PLC. Tujuan dari perancangan dan pembuatan prototipe mesin konveyor dan penghitungan barang untuk efisiensi [8]. Dalam dunia industri diperlukan suatu alat yang mampu beroperasi dengan cepat dan tepat sehingga proses produksi dapat berjalan dengan lebih efektif dan efisien, serta dapat meningkatkan kualitas dan jumlah hasil produksi. Tujuan penelitian ini adalah merancang sebuah model prototype mesin pengepakan dan penyortiran barang yang dikendalikan secara otomatis oleh pengendali PLC [9]. Rancang-Bangun Prototipe Sistem Kontrol Berbasis Programmable Logic Controller untuk Pengoperasian Miniatur Penyortiran Material. Proses dan hasil dalam hal pengontrolan merupakan indikator kinerja prototipe sistem berupa keakuratan pembacaan pulse dan ketepatan waktu penyortiran, didapatkan hasil bahwa pembacaan pulse dari proximity detect berpengaruh pada perhitungan counter sebagai perintah untuk pengaktifan pneumatic cylinder unit dalam penyortiran [10].

Untuk merancang desain pengemasan dan penghitungan barang secara otomatis ini dibutuhkan beberapa perangkat yaitu:

1. PLC. PLC digunakan sebagai alat pengontrol dalam mengeksekusi suatu perintah. PLC dapat di program sesuai dengan keinginan dari pembuat projek. Berikut jenis PLC yang digunakan dalam peancangan system, PLC yang digunaka Tipe CP 1L dengan 40 I/O.

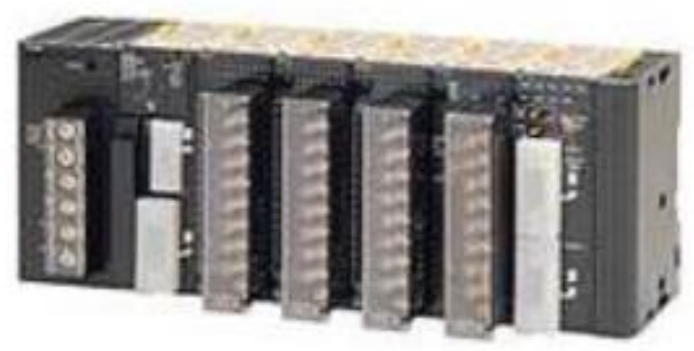

2. Sensor Infrared

Gambar 1 Programmable Logic Unit (PLC)

Sensor Infrared adalah komponen elektronika yang dapat mendeteksi benda ketika cahaya infra merah terhalangi oleh benda.Sensor infared terdiri dari led infrared sebagai pemancar dan fototransistor sebagai penerima cahaya infra merah [11].

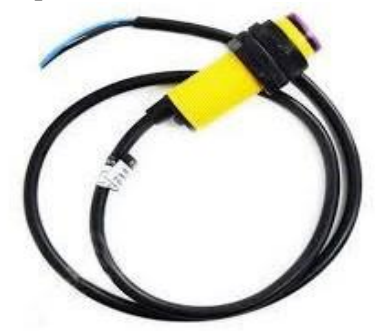

Ganbar 2 Sensor Infrared

3. Motor DC

Motor DC adalah motor listrik yang memerlukan suplai tegangan arus searah(DC)pada kumparan medan untuk diubah menjadi energi gerak mekanik. Kumparan medan pada motor dc disebut 
stator (bagian yang tidak berputar) dan kumparan jangkar disebut rotor (bagian yang berputar)

4. Karet untuk konveyor

\section{METODE PENELITIAN}

\section{Desain Perancangan Konveyor}

Rancangan Counter dan pengemasan barang menggunakan 2 unit konveyor. Konveyor terdiri dari 2 bagian yaitu untuk penggerak barang dan penggerak Kotak sebagai wadah barang. Untuk menghitung jumlah barang dan pengepakan barang menggunakan 2 sensor Infrared. Desain prototype konveyor dapat di lihat pada Gambar 3 dan Alamat I/O di sajikan pada Tabel 1.

Tabel 1 Alamat I/O pada PLC

\begin{tabular}{|l|l|l|l|l|}
\hline No & \multicolumn{1}{|c|}{$\begin{array}{c}\text { Alamat } \\
\text { Input/Output }\end{array}$} & \multicolumn{1}{c|}{ Fungsi } & \multicolumn{1}{c|}{ I/O } & \multicolumn{1}{c|}{ Keterangan } \\
\hline 1 & 0.00 & Tombol Start & Masukan & Work Area (WA) \\
\hline 2 & 0.01 & Tombol Reset & Masukan & Work Area \\
\hline 3 & W0.00 & Work Area & Keluaran & Alamat untuk WA \\
\hline 4 & 0.02 & Sensor Box & Masukan & Pendeteksi Kotak Wadah Barang \\
\hline 5 & 0.03 & Sensor Barang & Masukan & Pendeteksi dan penghitung Barang \\
\hline 6 & $\mathrm{C} 000$ & Counter & Masukan & Alamat Counter \\
\hline 7 & 100.00 & Conveyor Barang & Keluaran & Alamat Conveyor \\
\hline 8 & 100.01 & Conveyor Kotak & Keluaran & Alamat Conveyor $($ Box $)$ \\
\hline
\end{tabular}

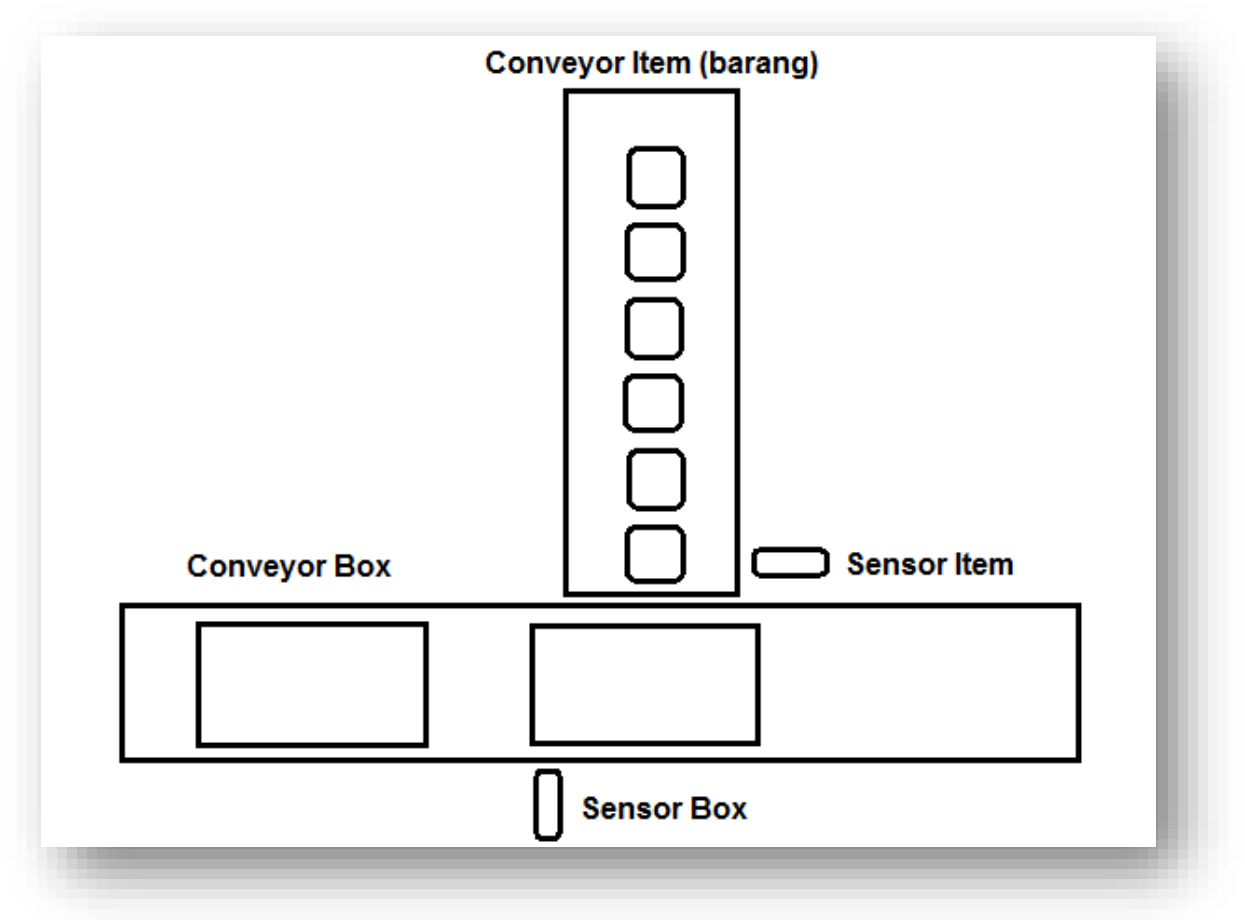

Gambar 3 Desain Konveyor Barang

1. Menggunakan Work Area (wa)

2. Ketika wa diaktifkan, maka Conveyor Box akan aktif.

3. Pada saat sensor box mendapat input high (box datang) maka Conveyor Box berhenti dan Conveyor Barang aktif dan menggerakan item. 
4. Sensor item akan mendeteksi sebanyak 5 item, setelh 5 item, maka Conveyor Barang akan berhenti dan Conveyor barang akan bergerak membawa Box (sensor Box masih high dan saat sensor box low (box berlalu) Conveyor Box masih Bergerak sampai Sensor Box mendeteksi Box berikutnya. Proses akan berulang ke nomor 3 .

5. Ketika tombol reset di tekan, maka semua akan berhenti.

\section{HASIL DAN PEMBAHASAN}

Pemrograman PLC menggunakan Ladder diagram. Software yang di gunakan adalah CX Programmer versi 9.5. berikut hasil pemrograman yang telah di buat di sajikan pada Gambar 4. Pada saat work area di aktifkan, maka sistem akan aktif. Fungsi adanya work area adalah sebagai emergency dima ketika terjadi suatu permasalah dengan mesin, maka cukup menekan tombol reset untuk mematikan sistem.

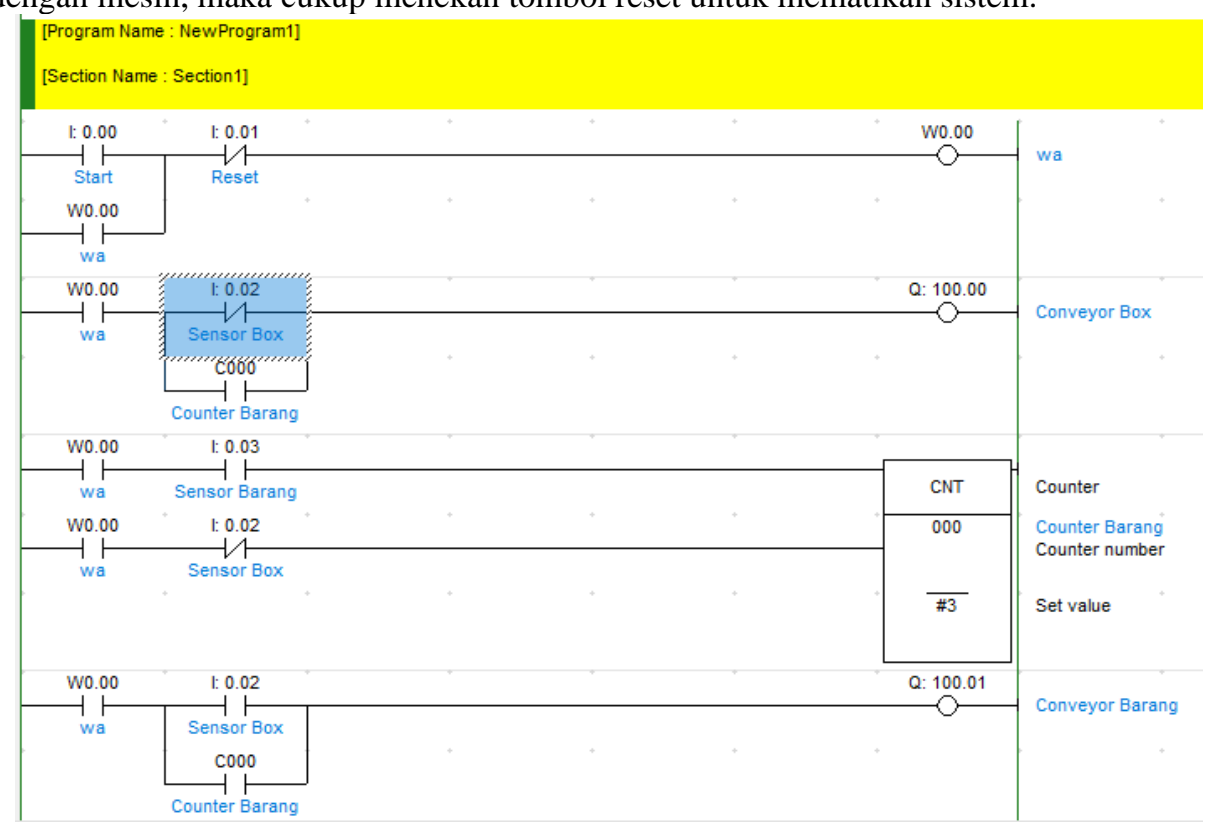

Gambar 4 Ladder Diagram Counter On dengan Work Area

Setelah Program telah di buat, selanjutnya adalah pengujian program sesuai dengan perancangan yang telah di buat. Berikut dilakukan pengujian pada program Ladder Diagram. Ketika work area on, maka sistem akan bekerja. Konveyor Kotak akan aktif dan menggerakan Kotak Barang (Box). Ketika Kotak mengenai Sensor Kotak(sensor box) maka Konveyor Bawah (box) akan mati. 


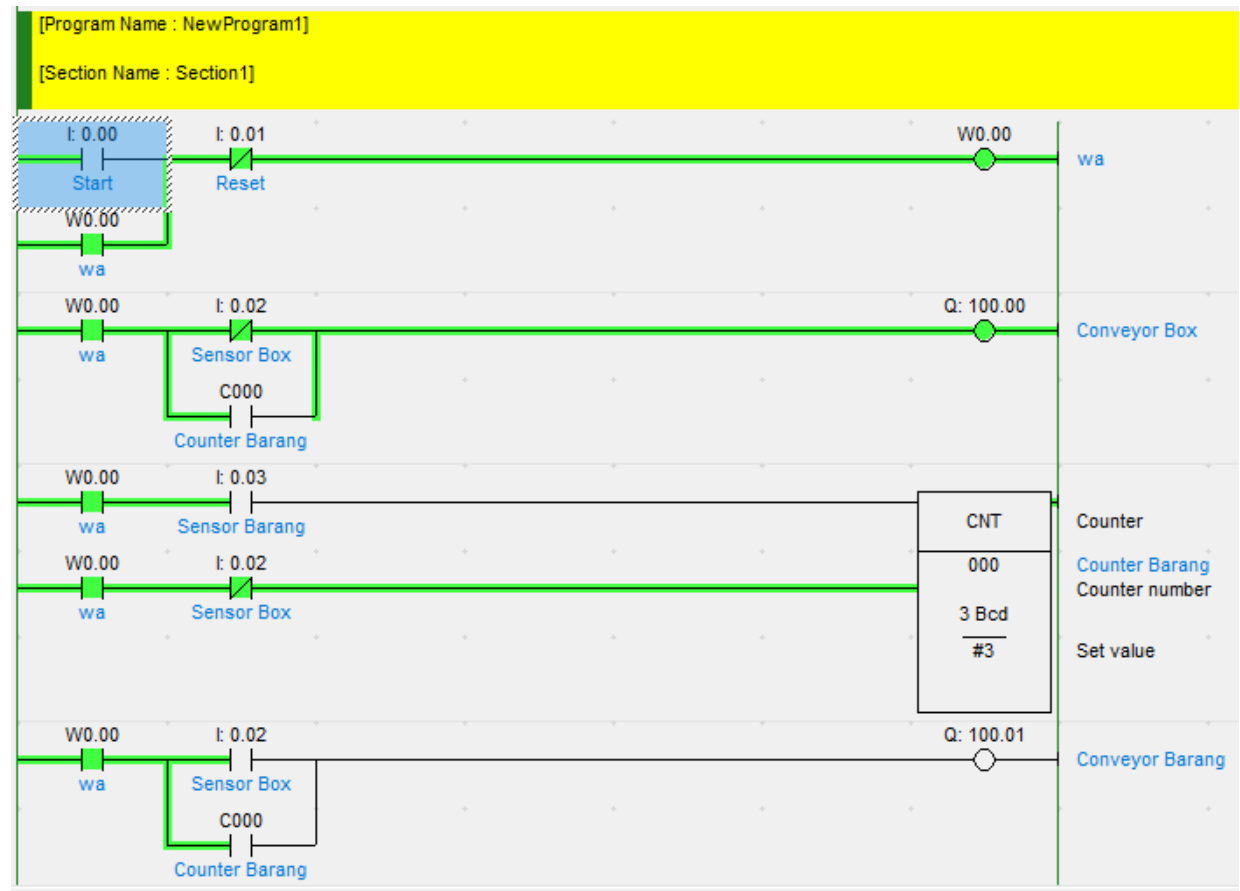

Gambar 5 Sensor Bawah High

Pada saat Sensor Box bernilai satau (membaca ada Box), maka akan mentriger Conveyor Barang untuk aktif. Kemudian counter akan mulai menghitung sebanyak tiga barang. Setelah tiga barang terbaca, Conveyor Barang mati dan Konveyor Box akan aktif kembali. Proses akan berulang hingga tombol reset di tekan.

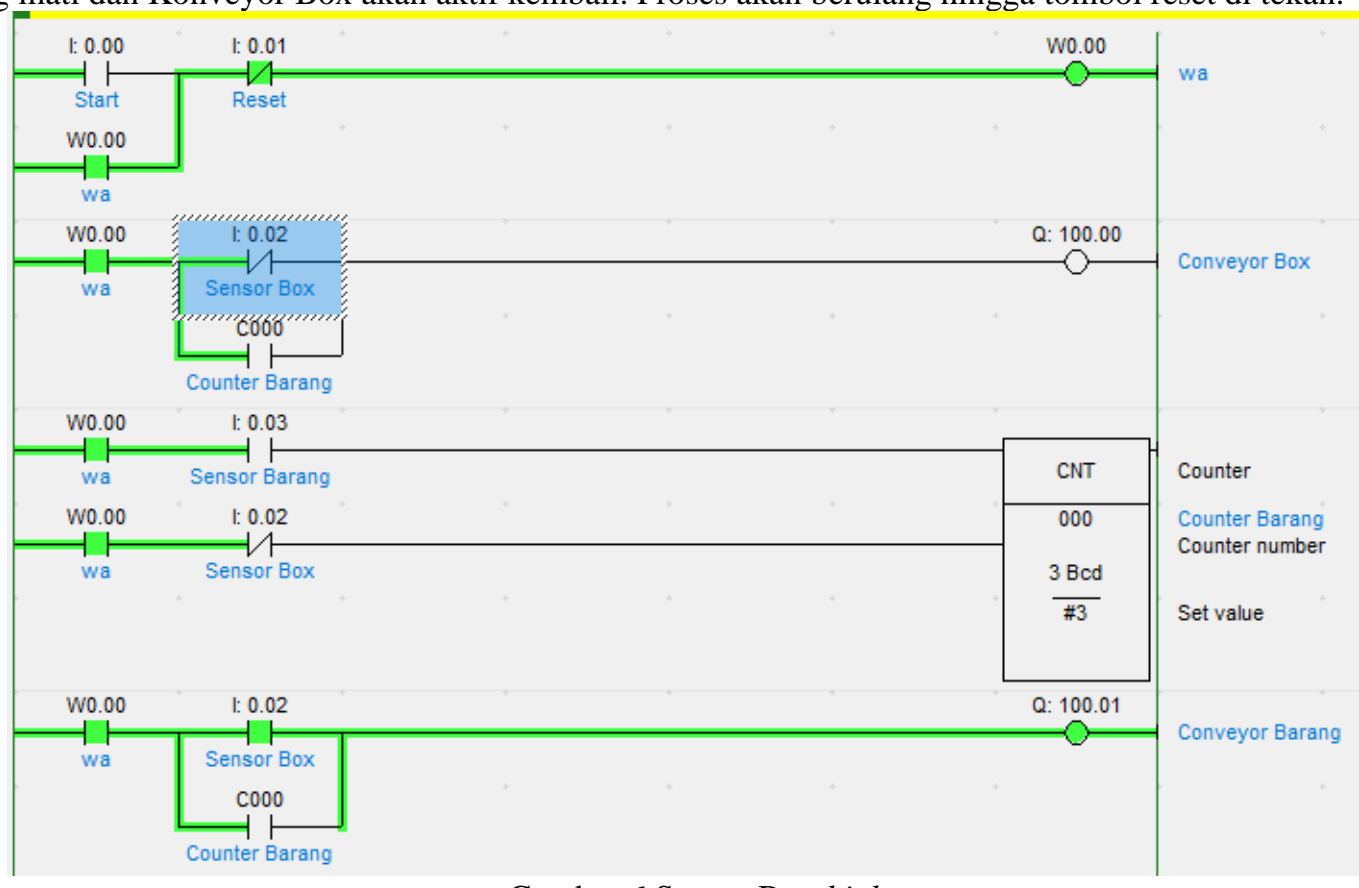

Gambar 6 Sensor Box high

Berikut adalah hasil penggujian Ladder Diagram menggunakan work area yang di sajikan pada Tabel 1.

\begin{tabular}{|l|c|c|c|}
\hline No & Skenario Pengujian & Hasil Pengujian & Kesimpulan \\
\hline 1 & Memberi nilai 1 pada sensor & Tidak ada yang aktif & Sistem belum bekerja sebelum \\
\hline
\end{tabular}




\begin{tabular}{|c|c|c|c|}
\hline & $\begin{array}{l}\text { bawah tanpa mengaktifkan } \\
\text { work area }\end{array}$ & & work area di aktifkan \\
\hline 2 & Mengaktifkan work area & Sistem aktif & $\begin{array}{l}\text { Konveyor Box akan berjalan } \\
\text { membawa Kotak Barang }\end{array}$ \\
\hline 3 & $\begin{array}{l}\text { Memberi nilai high (1) pada } \\
\text { sensor Box }\end{array}$ & $\begin{array}{l}\text { Konveyor Kotak Barang } \\
\text { Berhenti dan konveyor barang } \\
\text { (item bergerak membawa } \\
\text { barang }\end{array}$ & $\begin{array}{l}\text { Ketika sensor Box bernilai } 1 \\
\text { maka Konveyor Box akan } \\
\text { berhenti dan konveyoe barang } \\
\text { berjalan. }\end{array}$ \\
\hline 4 & $\begin{array}{l}\text { Memberi nilai 1dan } 0 \text { sebanyak } \\
3 \text { kali pada sensor barang (item) }\end{array}$ & $\begin{array}{l}\text { Counter akan berjalan mundur } \\
\text { (aktif) }\end{array}$ & $\begin{array}{l}\text { Pada saat barang (item) } \\
\text { melewati sensor barang, maka } \\
\text { counter akan menghitung } \\
\text { (maksimal } 3 \text { barang). Setelah } \\
\text { menghitung } 3 \text { barang (item), } \\
\text { maka Konveyor barang akan } \\
\text { berhenti. }\end{array}$ \\
\hline 5 & $\begin{array}{l}\text { Pada saat sensor Box bernilai } 0 \\
\text { (Box berlalu dari sensor) }\end{array}$ & $\begin{array}{l}\text { Konveyor Box tetap berjalan } \\
\text { sampai sensor Box mendapat } \\
\text { masukan lagi (bernilai 1) }\end{array}$ & $\begin{array}{l}\text { Konveyor Box tetap berjalan } \\
\text { sampai sensor Box mendapat } \\
\text { masukan lagi (bernilai 1) saat } \\
\text { Box berikutnya mengenai } \\
\text { sensor Box. Pada saat Box } \\
\text { berikutnya mengenai sensor } \\
\text { Box, Konveyor akan berhenti. } \\
\text { Proses akan berulang. }\end{array}$ \\
\hline
\end{tabular}

\section{SIMPULAN}

Bersarakan asil pengujian Program Eskalator yang di program menggunakan aplikasi CX Programmer, maka dapa di simpulkan:

1. Sistem belum bekerja sebelum work area di aktifkan

2. Konveyor Box akan berjalan membawa Kotak Barang

3. Ketika sensor Box bernilai 1 maka Konveyor Box akan berhenti dan konveyoe barang berjalan.

4. Pada saat barang (item) melewati sensor barang, maka counter akan menghitung (maksimal 3 barang). Setelah menghitung 3 barang (item), maka Konveyor barang akan berhenti.

5. Konveyor Box tetap berjalan sampai sensor Box mendapat masukan lagi (bernilai 1) saat Box berikutnya mengenai sensor Box. Pada saat Box berikutnya mengenai sensor Box, Konveyor akan berhenti. Proses akan berulang.

\section{DAFTAR PUSTAKA}

[1] R. Jaramaya, "Pengemasan di Industri Makanan dan Minuman Diambil Alih Robot," republika.co.id, 2016. https://republika.co.id/berita/ekonomi/makro/16/07/25/oauvvp382-pengemasan-di-industrimakanan-dan-minuman-diambil-alih-robot (accessed Jan. 07, 2021).

[2] B. Wulandari and H. D. Surjono, "Pengaruh problem-based learning terhadap hasil belajar ditinjau dari motivasi belajar PLC di SMK," J. Pendidik. Vokasi, vol. 3, no. 2, pp. 178-191, 2013, doi: 10.21831/jpv.v3i2.1600.

[3] D. Susandi, A. Rachmat, Y. Samantha, and G. Priyatna, "Perancangan Mesin Pemotongan Bahan Baku Genteng Dengan Sistem Kendali Plc Logic Smart Relay(Sr3B101Fu),” J-Ensitec, vol. 2, no. 01, pp. 4145, 2015, doi: 10.31949/j-ensitec.v2i01.50.

[4] S. Samsugi and A. Burlian, "Sistem Penjadwalan Pompa Air Otomatis Pada Aquaponik Menggunakan Mikrokontroler Arduino Uno R3,” pp. 187-197, 2019.

[5] S. D. R. I Komang, "Rancang Bangun Sistem Pengunci Loker Otomatis Dengan Kendali Akses Menggunakan Rfid Dan Sim 800L,” J. Ilm. Mhs. Kendali dan List., vol. 1, no. 1, pp. 33-41, 2020.

[6] P. Oktarin, N. U. Putri, and R. Setiawan, "Pengembangan alat ukur batas kapasitas tas sekolah anak berbasis mikrokontroler," vol. 1, no. 1, pp. 14-22, 2020.

[7] E. M. Indrawati and Nadliroh, "Rancang Bangun Dan Pemrograman Programmable Logic Controller 
(Plc) Berbasis Mikrokontroler Atmega32,” pp. 125-132, 2018.

[8] S. P. Sari, "Rancang Bangun Konveyor Penghitung Barang Dengan Sistem Kendali Berbasis PLC," J. Ilm. Teknol. Rekayasa, vol. 15, no. 100, pp. 168-175, 2014.

[9] H. Ardiansyah, N. Taryana, and D. Nataliana, "Perancangan Simulator Sistem Pengepakan dan Penyortiran Barang berbasis PLC Twido," J. Reka Elkomnika, vol. 1, no. 4, pp. 373-385, 2013.

[10] M. Latief, N. Kandowangko, and R. Yusuf, "Rancang-Bangun Prototipe Sistem Kontrol Berbasis Programmable Logic Controller untuk Pengoperasian Miniatur Penyortiran Material," J. Rekayasa Elektr., vol. 13, no. 36, pp. 152-160, 2017, doi: 10.17529/jre.v16i3.14905.

[11] M. Ruswandi Djalal, D. Ajiatmo, A. Imran, and I. Robandi, "Desain Optimal Kontroler Pid Motor Dc Menggunakan Cuckoo Search Algorithm," NitishKatal.BharatBhushan.AshuAhuja.AnantOonsivilai.UmeshKumarBansal, vol. 7, pp. 121-126, 2014. 